\title{
STATUS REPRODUKSI DAN ESTIMASI OUTPUT KAMBING SABURAI DI DESA GISTING ATAS KECAMATAN GISTING KABUPATEN TANGGAMUS
}

\author{
Reproduction Status and Output Estimation of Saburai Goat in Gisting Atas Village \\ Gisting Subdistrict Tanggamus Regency
}

Kusuma Adhianto, Siswanto, Sulastri, dan Anggi Derma Tungga Dewi

Department of Animal Husbandry, Faculty of Agriculture, Lampung University

Jl. Soemantri Brojonegoro No. 1, Gedong Meneng, Rajabasa, Bandar Lampung 35145

Email : kusuma.adhianto@fp.unila.ac.id

\begin{abstract}
The goal of this study was to identify reproduction status, Natural Increase, Net Replacement Rate, and output estimation of Saburai Goat in Gisting Atas village, Gisting subdistrict, Tanggamus regency. This research was conducted in March until April 2018. The material of this study is all of the Saburai goats which was available in the Gisting Atas Village, which number 89 heads. The results showed that the reproduction status of Saburai Goat in Gisting Atas Village were : first matingfor male goats was 15.47 months and for female goats was12.05 months, Post partum mating was for 2.67 months, calving interval was for 8.67 months. natural increase of Saburai goats was 24.72\%, net replacement rate of male goats was $234.92 \%$, and female goats was $121.62 \%$, and the output Saburai goats was $24.72 \%$ (28 goats).
\end{abstract}

Keywords: Reproduction Status, Natural Increase, Net Replacement Rate, Output Estimation, Saburai Goat

\section{PENDAHULUAN}

Kambing saburai merupakan persilangan antara kambing Peranakan Etawa (PE) betina dengan kambing Boer jantan. Kambing Saburai merupakan rumpun kambing yang ditetapkan oleh Menteri Pertanian Republik Indonesia Nomor 359/Kpts/PK.040/6/2015 sebagai sumberdaya genetik lokal Provinsi Lampung (Adhianto et al., 2015). Kambing tersebut merupakan hasil persilangan secara grading up sampai tahap kedua (Dinas Peternakan dan Kesehatan Hewan Provinsi Lampung, 2015). Rendahnya populasi kambing Saburai disebabkan karena belum terkontrolnya perkawinan di lokasi tersebut, perkawinan seharusnya hanya dilakukan antara kambing Saburai jantan dengan kambing Saburai betina yang memiliki karakteristik kinerja pertumbuhan tinggi sehingga dihasilkan keturunan dengan kinerja pertumbuhan yang lebih tinggi daripada kedua tetuanya. Selain itu penampilan reproduksi dari kambing saburai masih sangat rendah seperti tingginya umur saat kawin, tingginya $\mathrm{S} / \mathrm{C}$, dan panjangnya periode post partum estrus dan calving interval.
Peningkatan produktivitas ternak dapat ditempuh melalui perbaikan sistem pemeliharaan dan pengelolaan reproduksi. Manajemen reproduksi berpengaruh terhadap tingkat kelahiran dan kematian ternak. Tingkat kelahiran dan kematian ternak berpengaruh terhadap nilai pertumbuhan populasi secara alamiah yang disebut natural increase (NI). Nilai NI berpengaruh terhadap kemampuan wilayah dalam menyediakan ternak pengganti yang dihitung dari selisih antara presentase kelahiran dengan kematian ternak. Sisa ternak pengganti berpengaruh terhadap besarnya output. Estimasi output merupakan merupakan hasil penjumlahan sisa ternak pengganti (replacement stock) jantan dan betina dan ternak afkir jantan dan betina (Zahra, 2016).

Informasi tentang evaluasi terhadap kinerja reproduksi dan estimasi output kambing Saburai di Desa Gisting Atas Kecamatan Gisting Kabupaten Tanggamus perlu dilakukan untuk mengetahui potensi populasi kambing Saburai melalui penelitian tentang status reproduksi dan estimasi output kambing Saburai di Desa Gisting Atas Kecamatan Gisting Kabupaten Tanggamus. 


\section{MATERI DAN METODE}

\section{Materi}

Materi penelitian terdiri semua kambing Saburai di lokasi penelitian dan kuisioner untuk peternak.

\section{Metode}

Metode penelitian yang digunakan adalah metode survei dengan teknik pengambilan data secara sensus sehingga semua kambing Saburai yang terdapat di lokasi penelitian digunakan sebagai bahan pengamatan. Data primer diperoleh melalui wawancara dengan peternak. Data primer yang diambil meliputi jumlah kepemilikan ternak, identitas responden, manajemen pemeliharaan, dan data reproduksi.

\section{Analisis Data}

Data populasi dan data reproduksi digunakan untuk menghitung nilai NI, NRR, dan output melalui pendekatan teori pemuliaan ternak sesuai dengan rekomendasi Hardjosubroto (1994) dan Sumadi et al. (2004).

Tabel 1. Manajemen reproduksi kambing Saburai

\begin{tabular}{|c|c|c|}
\hline No. & Variabel Peubah & Nilai Variabel Peubah \\
\hline 1. & Jumlah sampel induk (ekor) & 38 \\
\hline 2. & Jumlah sampel jantan dewasa (ekor) & 15 \\
\hline \multirow[t]{5}{*}{3.} & Pengenalan tanda birahi & \\
\hline & a. Baik sekali $(\%)$ & 100,00 \\
\hline & b. Baik $(\%)$ & 0,00 \\
\hline & c. Cukup (\%) & 0,00 \\
\hline & d. Kurang (\%) & 0,00 \\
\hline \multirow[t]{4}{*}{4.} & Cara perkawinan & \\
\hline & a. $\operatorname{IB}(\%)$ & 0,00 \\
\hline & b. Alami $(\%)$ & 100,00 \\
\hline & c. Campuran $(\%)$ & 0,00 \\
\hline \multirow[t]{4}{*}{5.} & Umur kawin pertama (bulan) & \\
\hline & a. Jantan & $15,47 \pm 4,66$ \\
\hline & b. Betina & $12,05 \pm 3,97$ \\
\hline & Lama bunting (bulan) & $5,89 \pm 0,31$ \\
\hline 6. & Post Partum Mating (PPM) (bulan) & $2,67 \pm 0,49$ \\
\hline 7. & Umur sapih (bulan) & $3,92 \pm 0,76$ \\
\hline 8. & Interval beranak (bulan) & $8,67 \pm 0,49$ \\
\hline \multirow[t]{3}{*}{9.} & Batas umur pemeliharaan (tahun) & \\
\hline & a. Jantan & $4,67 \pm 0,59$ \\
\hline & b. Betina & $5,38 \pm 1,31$ \\
\hline \multirow[t]{4}{*}{10.} & Jumlah kelahiran & \\
\hline & a. Jantan (ekor) & 17 \\
\hline & b. Betina (ekor) & 19 \\
\hline & c. Litter size (ekor) & 1,35 \\
\hline \multirow[t]{3}{*}{11.} & Lama digunakan dalam pembiakan (tahun) & \\
\hline & a. Jantan (tahun) & $3,08 \pm 0,57$ \\
\hline & b. Betina (tahun) & $4,38 \pm 1,31$ \\
\hline
\end{tabular}

\section{HASIL DAN PEMBAHASAN}

\section{Manajemen Reproduksi Ternak Kambing}

Hasil penelitian yang disajikan pada Tabel 1 menunjukkan bahwa seluruh kambing Saburai di Desa Gisting Atas dikawinkan secara alami sehingga peternak tidak memerlukan bantuan inseminator untuk melakukan inseminasi buatan. Cara perkawinan dilakukan dengan menyatukan kambing jantan dengan kambing betina di kandang yang sama sehingga pejantan dapat segera mengawini betina.

\section{Cara Perkawinan}

Hasil penelitian menunjukan bahwa seluruh kambing Saburai di Desa Gisting Atas dikawinkan secara alami, karena di lokasi penelitian masih banyak peternak yang memiliki pejantan Boer, namun peternak kambing tersebut ada yang memiliki pejantan dan ada yang tidak, peternak yang tidak memiliki pejantan bisa meminjam pejantan dari peternak lain. Menurut Budiarsana dan Sutama (2001) perkawinan secara alamiah pada kambing masih merupakan cara paling praktis dengan tingkat kebuntingan mencapai $84-100 \%$. 


\section{Umur Perkawinan Pertama}

Hasil penelitian menunjukkan bahwa umur pertama kawin pada kambing jantan yaitu 15,47 bulan dan pada kambing betina yaitu 12,05 bulan (Tabel 1) Kambing jantan pada umumnya mencapai dewasa kelamin pada umur 15 - 18 bulan dan mulai dikawinkan umur 24 bulan, sedangkan kambing betina mencapai dewasa kelamin pada umur $8-9$ bulan, namun baru dapat dikawinkan pada umur 12 bulan (Murtidjo, 1993). Hasil penelitian Sulastri dan Adhianto (2016) menunjukkan bahwa umur pertama kali kawin pada kambing Saburai yaitu kambing jantan pada umur 22,97 bulan dan kambing betina pada umur 16,28 bulan. Perbedaan umur pertama kali kawin dikarenakan adanya perbedaan manajemen pemeliharaan peternak disetiap daerah.

\section{Perkawinan Setelah Beranak}

Perkawinan kembali setelah beranak atau post partum mating (PPM) pada hasil penelitian menunjukkan bahwa pada kambing Saburai yaitu 2,67 bulan, dengan lama bunting yaitu selama 5,89 bulan. Hasil periode PPM tersebut termasuk normal karena menurut Lestari (2009), periode PPM yang maksimal adalah 2 bulan, maka kambing dapat bunting kembali 3 bulan setelah beranak.

\section{Umur Sapih}

Umur sapih cempe Saburai pada hasil penelitian ini yaitu 3,92 bulan. Umur sapih ini termasuk tinggi karena dibandingkan dengan hasil penelitian dari Sulastri dan Adhianto (2016) menunjukkan bahwa umur sapih cempe Saburai yaitu 2,51 bulan. Peternak melakukan penyapihan setelah dirasa cempe cukup mampu mandiri dan induk sudah menunjukkan kebuntingan. Kambing-kambing yang sedang menyusui dan sudah menunjukkan gejala birahi segera dikawinkan dan dipisahkan dari cempe apabila cempe sudah dipandang cukup dalam perawatan induk (Sulastri dan Adhianto, 2016).

\section{Interval Beranak}

Hasil penelitian pada Tabel 1 menunjukkan interval beranak (calving interval) kambing Saburai yaitu 8,67 bulan. Menurut Sutama (2007) interval beranak kambing lokal pada umumnya bervariasi antara 7 sampai 8 bulan. Faktor penentu panjangnya interval beranak yaitu timbulnya gejala birahi setelah beranak pertama, perkawinan setelah beranak (PPM), serta service per conception (S/C). Faktor lain yang menyebabkan perbedaan lama interval beranak adalah tingkat daya tahan trenak akibat pengaruh cekaman stress (Elieser et al., 2012).

\section{Batas Umur Pemeliharaan dan Lama Penggunaan dalam Populasi}

Hasil penelitian menunjukkan bahwa pada kambing betina lama penggunaannya yaitu selama 4,38 tahun, sedangkan kambing jantan lama penggunaannya yaitu selama 3,08 tahun. Hal tersebut disebabkan karena harga jual kambing pejantan lebih tinggi daripada kambing betina, sehingga peternak memilih untuk menjuaal kambing jantannya daripada kambing betina pada saatmembutuhkan uang.

Penggunaan betina dalam populasi paling lama sampai beranak sekitar 6-7 kali. Semakin lama betina dipelihara, maka semakin banyak cempe yang dilahirkan. Sesuai dengan pendapat dari Devandra dan Burns (1994) yang menyatakan bahwa bangsa-bangsa kambing di daerah tropis biasaya beranak pertama kali pada umur 1 tahun dan dapat digunakan dalam pembiakan sampai kambing berumur 5-6 tahun. Kambing jantan dapat dikawinkan mulai umur 10 bulan, tetapi hanya dapat mengawini kambing betina tidak lebih dari 20 ekor dan maksimal dua kali dalam seminggu sebelum umurnya genap 1 tahun (Hoda, 2008).

\section{Natural Increase}

Hasil penelitian pada Tabel 2 menunjukkan bahwa nilai Natural Increase (NI) kambing Saburai yaitu 24,72\% sehingga termasuk kategori tinggi. Klasifikasi nilai NI dapat dilihat pada Tabel 3. Nilai NI dapat mencapai maksimal apabila persentase kelahiran anak terhadap populasi tinggi dan tingkat kematian rendah (Sumadi et al., 2004). Tingkat kelahiran cempe dipengaruhi oleh fertilitas induk dan manajemen pemeliharaan. Tingkat kematian dipengaruhi oleh ketahanan hidup ternak dan manajemen pemeliharaan (Sumadi et al., 2004).

Tabel 2. Nilai NI kambing Saburai di Desa Gisting Atas

\begin{tabular}{clr}
\hline No. & Variabel Peubah & Nilai Variabel Peubah \\
\hline 1. & Jumlah kelahiran cempe (ekor) & 31 \\
2. & Jumlah kelahiran cempe jantan (ekor) & 16 \\
3. & Jumlah kelahiran cempe betina (ekor) & 15 \\
4. & Total populasi per bangsa kambing (ekor) & 89
\end{tabular}




\begin{tabular}{clr}
\hline No. & Variabel Peubah & Nilai Variabel Peubah \\
\hline 5. & Jumlah kematian kambing/tahun (ekor) & 9 \\
6. & Persentase kelahiran cempe terhadap populasi (\%) & 34,83 \\
7. & Persentase kematian kambing terhadap populasi (\%) & 10,11 \\
8. & NI 12 bulan (\%) & 24,72 \\
& Kelas NI & Tinggi \\
9. & NI 12 bulan kelompok kambing jantan (\%) & 12,85 \\
& Kelas NI & sedang \\
10. & NI 12 bulan kelompok kambing betina (\%) & 11,87 \\
& Kelas NI & sedang \\
\hline
\end{tabular}

Tabel 3. Klasifikasi NI kambing Saburai

\begin{tabular}{cr}
\hline Kategori & Kambing Saburai \\
\hline Rendah & $0,00--8,24$ \\
Sedang & $>8,24--16,48$ \\
Tinggi & $>16,48--24,72$ \\
\hline
\end{tabular}

Sumber : Sumadi et al. (2004)

\section{Net Replacement Rate}

Hasil penelitian pada Tabel 4 menunjukkan bahwa nilai Net Replacement Rate (NRR) pada kambing Saburai lebih dari $100 \%$. Hal tersebut berarti bahwa lokasi penelitian mampu menyediakan calon tetua pengganti jantan dan betina sendiri. Nilai NRR kambing jantan pada hasil penelitian yaitu $234,92 \%$ atau mengalami surplus sebesar $134,92 \%$ dan nilai NRR kambing betina yaitu $121,62 \%$ atau mengalami surplus sebesar $21,62 \%$. Nilai NRR kambing jantan lebih tinggi daripada kambing betina, hal tersebut disebabkan karena menurut Aprilinda (2016) perbedaan imbangan kebutuhan replacement dengan ketersediaan kambing muda sebagai ternak pengganti.

Menurut Sumadi et al. (2004) faktor-faktor yang berpengaruh terhadap NRR adalah kemampuan wilayah dalam menyediakan ternak pengganti dan kebutuhan ternak pengganti per tahun. Kebutuhan ternak pengganti ditentukan oleh lama penggunaan ternak jantan dan betina dalam populasi. Kebutuhan ternak pengganti cukup tinggi apabila lama penggunaan ternak dalam jangka waktu yang pendek. Sebaliknya, kebutuhan ternak pengganti dalam suatu wilayah rendah apabila lama penggunaan ternak cukup panjang.

Tabel 4. Nilai NRR kambing Saburai di Desa Gisting Atas

\begin{tabular}{clr}
\hline No. & Variabel Peubah & Nilai Variabel Peubah \\
\hline 1 & Kebutuhan replacement jantan & \\
a. Jumlah jantan dewasa (ekor) & 15 \\
b. Persentase (\%) & 16,85 \\
c. Lama digunakan dalam pembiakan (tahun) & 3,08 \\
d. Kebutuhan replacement jantan per tahun (\%) & 5,47 \\
Kebutuhan replacement betina & \\
a. Jumlah betina dewasa(ekor) & 38 \\
b. Persentase (\%) & 42,7 \\
c. Lama digunakan dalam pembiakan (tahun) & 4,38 \\
d. Kebutuhan replacement betina per tahun (\%) & 9,76 \\
Sisa replacement & \\
a. Sisa replacement jantan (\%) & 7,38 \\
b. Sisa replacement betina (\%) & 2,11 \\
NRR (rata-rata) dalam \% & \\
a. NRR jantan (\%) & 234,92 \\
b. NRR betina (\%) & 121,62 \\
\hline
\end{tabular}

\section{Estimasi Output}

Hasil penelitian pada Tabel 5 menunjukkan bahwa nilai estimasi output kambing Saburai yaitu 27,66\% (28 ekor). Faktor yang berpengaruh terhadap besarnya output adalah pola perkembangbiakan ternak dalam populasi. Pola perkembangbiakan tersebut antara lain sistem perkawinan pada ternak dan lamanya 
penggunaan ternak jantan dan betina dewasa dalam populasi. Banyaknya sisa ternak pengganti dan afkir yang dapat dikeluarkan dari suatu wilayah dipengaruhi oleh lamanya penggunaan ternak jantan dan betina (Sumadi et al., 2004).

Tabel 5. Estimasi output kambing Saburai

\begin{tabular}{clr}
\hline No. & Variabel Peubah & Nilai Variabel Peubah \\
\hline 1. & Total populasi (ekor) & 89 \\
2. & Kambing jantan afkir (\%) & 5,47 \\
& Kambing jantan afkir (ekor) & 6 \\
3. & Kambing betina afkir (\%) & 9,76 \\
& Kambing betina afkir (ekor) & 11 \\
4. & Sisa replacement jantan (\%) & 7,38 \\
& Sisa replacement jantan (ekor) & 8 \\
5. & Sisa replacement betina (\%) & 2,11 \\
& Sisa replacement betina (ekor) & 2 \\
6. & Totalestimasi output (\%) & 24,72 \\
& Total estimasi output (ekor) & 28 \\
\hline
\end{tabular}

Besarnya kebutuhan ternak jantan dan betina yang digunakan dalam wilayah pembiakan merupakan presentase ternak muda dibagi dengan lama penggunaan ternak dalam populasi. Persentase kebutuhan ternak pengganti jantan dan betina dalam populasi sama besarnya dengan persentase kambing afkir jantan dan betina. Sisa ternak pengganti merupakan selisih antara ketersediaan ternak muda dengan kebutuhan ternak muda. Hal tersebut menunjukkan bahwa pola perkembangbiakan ternak berpengaruh terhadap komposisi output (Sumadi et al., 2004).

\section{SIMPULAN DAN SARAN}

\section{Simpulan}

Hasil penelitian menunjukkan bahwa status reproduksi dan natural increase kambing Saburai di Desa Gisting Atas, Kecamatan Gisting, Kabupaten Tanggamus sudah cukup baik, kondisi ini perlu dipertahankan dan lebih ditingkatkan dalam upaya menjadi wilayah sumber bibit kambing Saburai.

\section{Saran}

Perlu adanya pencatatan atau perhitungan pertambahan alami (natural increase) dan estimasi output populasi ternak dalam suatu wilayah yang dilakukan secara kontinyu setiap tahun sehingga perkembangan populasi ternak dapat diketahui dan bisa digunakan sebagai pedoman atau acuan dalam melakukan perencanaan program pengembangan ternak diwilayah tersebut.

\section{Ucapan Terima Kasih}

Ucapan terima kasih disampaikan kepada Kementerian Riset Teknologi dan Pendidikan Tinggi atas fasilitas yang diberikan pada penulis melalui pendanaan penelitian tahun 2018 dalam skim Penelitian Dasar Unggulan Perguruan Tinggi.

\section{DAFTAR PUSTAKA}

Adhianto, K., M. D. I. Hamdani, dan Sulastri. 2015. Model Kurva Pertumbuhan Pra Sapih Kambing Saburai di Kabupaten Tanggamus. Jurnal Sain Peternakan Indonesia. 10: 2: 95-100.

Aprilinda, S., Sulastri, dan S. Suharyati. 2016. Status Reproduksi dan Estimasi Output Bangsa-Bangsa Kambing di Desa Karang Endah Kecamatan Terbanggi Besar Kabupaten Lampung Tengah. Jurnal Ilmiah Peternakan Terpadu, 4:1: 55-62.

Budiarsana, I G.M. dan I K. Sutama. 2001. Fertilitas Kambing Peranakan Etawah pada Perkawinan Alami dan Inseminasi Buatan. Hlm. 85-92. Prosiding Seminar Nasional Peternakan dan Veteriner. Pusat Penelitian dan Pengembangan Peternakan, Bogor.

Devendra, C. dan M. Burns. 1994. Produksi Kambing di Daerah Tropis. Terjemahan : I. D. K. Harya Putra. Penerbit ITB. Bandung.

Dinas Peternakan dan Kesehatan Hewan Kabupaten Tanggamus. 2015. DataPopulasi Kambing.

ttp://bvetlampung.ditjennak.pertanian.go.id/ kambingsaburai-icon-peternakan-kambingdari-provinsi-lampung/. Diakses 10 Mei 2018

Elieser, S., Sumadi, G. Suparta, dan Subandriyo. 2012. Kinerja reproduksi induk Kambing Boer, Kacang dan Boerka. JITV.17 (2): 100 $-106$

Hoda, A. 2008. Studi Karakterisasi, Produktivitas, dan Dinamika Populasi Kambing Kacang 
(Capra Hicrus) untuk Program Pemuliaan Ternak Kambing di Maluku Utara. Disertasi. Sekolah Pascasarjana. Institut Pertanian Bogor. Bogor.

Lestari, A.R. 2009. Penampilan reproduksi kambing Jawarandu (Studi kasus diPT Widodo Makmur Perkasa, Propinsi Lampung). Skripsi. Fakultas Kedokteran Hewan. Institut Pertanian Bogor.

Murtidjo, B.A. 1993. Memelihara Kambing sebagai Ternak Potong dan Perah. Kanisius. Yogyakarta.

Sulastri dan K. Adhianto.2016. PotensiPopulasi Empat Rumpun Kambing Di Provinsi Lampung. Plantaxia. Yogyakarta.

Sumadi, W. Hardjosubroto dan N. Ngadiyono. 2004. Analisis potensi sapi potong bakalan di Daerah Istimewa Yogyakarta. Prosiding Seminar Nasional Teknologi Peternakan Dan Veteriner 2004, Hal: 130-139.

Sutama. I Ketut. 2007. Tantangan dan peluang peningkatan produktivitas kambing melalui inovasi teknologi reproduksi. Prosiding Lokakarya Nasional Kambing Potong. Pusat Penelitian dan Pengembangan Peternakan. Bogor.

Zahra, A. 2016. Status Reproduksi dan Potensi Populasi Berbagai Bangsa Sapi Di Desa Karang Endah Kecamatan Terbanggi Besar Kabupaten Lampung Tengah. Skripsi. Fakultas Pertanian. Universitas Lampung. 